\title{
Optimizing Trees Distances in Urban Streets for Insolation Mitigation
}

\author{
Ivana Bajsanski ${ }^{A^{*}}$, Vesna Stojakovic ${ }^{\mathrm{A}}$, Dragan Milosevic ${ }^{\mathrm{B}}$ \\ Received: November 29, 2019 | Revised: December 26, 2019 | Accepted: December 30, 2019 \\ DOI: $10.5937 / g p 23-24242$
}

\begin{abstract}
Mitigation of overheating in streets is an important task for urban planners and architects. Urban surfaces in streets, such as footways and façades, can contribute to increase overheating in cities, whereas the trees can help to decrease insolation.

In this paper we created an algorithm to determine optimal distance between the trees in a street in order to mitigate façade and footway insolation. A parametric study for different street orientations and building geometries was therefore conducted for the hottest wave of the year for the corresponding location. The results show that different trees disposition can mitigate overheating of horizontal and vertical surfaces up to $7 \%$. The algorithmic and parametric approach used in this paper can contribute to more precise urban design guidelines for comfortable streets.
\end{abstract}

Keywords: street; algorithm; insolation; façade; footways; trees

\section{Introduction}

The design of a street is a key issue in bioclimatic urban design methodology (Oke, 1988; Ali-Toudert \& Bensalem, 2001; Bajšanski et al. 2015). Due to this, in different urban areas inappropriate street design cause overheating of the surfaces. Numerous researches took into account this problem in order to obtain better conditions for human well-being in open urban spaces (Ali-Toudert \& Mayer, 2006; Andreou, 2014; Chan et al., 2001).

Geometry, orientation and position of the built environment have impact on urban surface level of insolation (Chatzidimitriou \& Yannas, 2017). Footways, bicycle path and parking lots, located in front of the buildings, which are exposed to the sun most of the day, can contribute to increasing temperature of these areas in cities (Andreou \& Axarli, 2012). Overheating of façades and surfaces in front of the façades can be solved with trees, taking into account its geometry, position and number. Many studies showed that trees are one of the most effective strategies for cooling of the urban environment (de Abreu-Harbich et al., 2015; Picot, 2004; Taleghani et al., 2016; Milošević et al. 2017a). The rapid development of various software applications which allows solar simulations and analysis, considering surrounding buildings and trees, can contribute to find practical solution of adequate trees disposition in streets (Simpson, 2002; D. Amado \& Poggi, 2014; Bajsanski et al., 2016; Milošević et al. 2017b).

In architectural and urban planning practice disposition of trees in streets depends on aesthetical reasons. Architects and urban planners often do not take into account entire geometry of the street, such as orientation, height of the buildings and street configuration (Baker et al., 2002).

\footnotetext{
A Department of Architecture and Urban Planning, Faculty of Technical Sciences, University of Novi Sad, Trg Dositeja Obradovića 6, 21000 Novi Sad, Serbia

B Climatology and Hydrology Research Centre, Faculty of Science, University of Novi Sad, Trg Dositeja Obradovića 3, 21000 Novi Sad, Serbia

* Corresponding author:Ivana Bajsanski, e-mail: ivana_b@uns.ac.rs, Tel: +381214852468
} 
The aim of this paper is to create an algorithm which determines the favorable distance between the trees in order to decrease façade and footway in- solation. Algorithm takes into account surrounding buildings, trees, location and street orientation as well as climate factors.

\section{Methodology}

\section{Methodology consists of several phases}

- First phase is modeling of the geometry of three-dimensional built environment. The $3 \mathrm{D}$ model can be created in any $3 \mathrm{~d}$ modelling program and imported into Rhinoceros in order to reference geometry in Grasshopper (https://www.rhino3d.com/6/new/ grasshopper). Models represent streets and they include the buildings and trees as solids with defined geometrical characteristics.

- In second phase, we created an algorithm in the visual programming software, Grasshopper (Rhinoceros plug-in), that automatically changes the distance between the trees in order to detect the favorable distance in the terms of surface insolation mitigation.
- Third phase includes exporting all geometry from Rhinoceros to Ecotect (Horvat and Dubois, 2012) software by using Geco (Grasshopper add on) for environmental analysis and solar simulations by taking into account weather data for chosen location of the street.

- Fourth phase includes calculation of insolation. All numerical results obtained by the solar simulations from Ecotect software are transferred to the Grasshopper.

- The last phase refers to detecting the minimal insolation value which corresponds to the favorable distance between trees, and hence determines the urban design recommendation for the distribution of trees in the street.

\section{Algorithm for detecting optimal trees distances}

The algorithm created in this paper estimates trees distances in order to provide minimal insolation on urban surfaces, buildings' façades and footways during the summer period. By changing the locations of predetermined number of trees on the footway, the insolation can be reduced.

\section{Geometry of built environment and trees distances}

Geometrical characteristic of the environment which are included in this research are:

- buildings' geometry,

- footway size and shape,

- trees' geometry.

Buildings' geometry has a significant influence on level of insolation of the footways. Geometry of the building is determined by its height and shape. The vertical surface is used in algorithm for representing façade and the footways are represented as a horizontal surface located in the front of the building.

One part of the footway is planted with trees. Trees' geometry is simplified and each tree is presented as a spherical solid. Dimensions of the trees include crown diameter $\mathrm{D}$ and height of the trunk. Centers of the tree trunks are located on a single line which represents the tree path. Trees are moved along the path, and after each change in distribution, the solar simulation program calculates insolation level. Maximal distance between the trees is determined by equal distribution of the trees on one segment of the footway, and minimal distance of the trees is dependent of the diameter in order to prevent overlapping of crowns.

\section{Solar simulations and detecting the favorable trees' distance}

Solar analyses are performed in Ecotect, software for solar analysis, which is connected with Grasshopper by Geco, Grasshopper add on. Geco allows simultaneously exporting geometry from Rhinoceros to Ecotect, and back simulation numerical results into Grasshopper. Numerical results can be exported in any spreadsheet software in order to detect differences between the resulting insolation values.

To perform solar simulations, we defined the climate data for target location and specified period of the year $(0-365$ day(s)) and day $(\mathrm{o}-24 \mathrm{~h}(\mathrm{~s}))$. The climate data is used for Belgrade, for summer period, from May $1^{\text {st }}$ to October $1^{\text {st }}$, because this period is leaf on period. 


\section{Results - Application of the algorithm}

The algorithm is tested on several examples of the streets with different distance between façade and footway and with different street orientation. Taking into account that streets are usually very long, with a lot of trees, the street is divided into the segments modelled and simulated individually. In order to perform calculation of solar analysis faster it is assumed that the number of trees is four in each segment.

Geometry inputs which are used in these street segments are:

- length of the façade - 3om;

- height of the façade $(\mathrm{H})$ - 11m;

- crown diameter - 5m;

- trunk height - 2.5m;

- footway length - 3om;

- footway width - $5 \mathrm{~m}$ to $12 \mathrm{~m}$ (with bicycle path).

\section{Façade and footway insolation}

The generated algorithm is tested on street with E-W orientation first. The solar insolation is calculated for the façade. In the first iteration four trees are placed in even distribution with maximum distance between the trees, with insolation $2129,1 \mathrm{Wh} /$ $\mathrm{m}^{2}$ (Figure 1). Algorithm is used to detect that the most favourable solution which cast maximal shadow on the façade is when distance between the trees

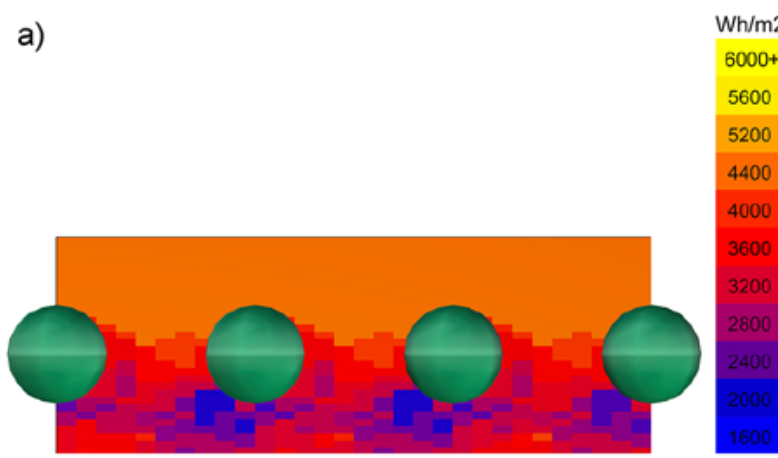

b)

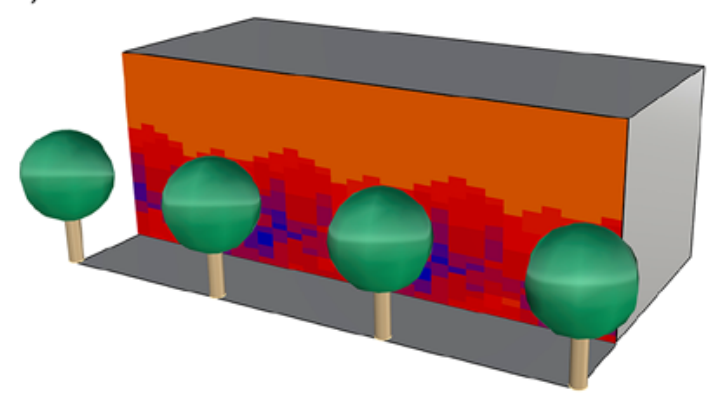

Figure 1. Insolation of the façade with maximal distance between trees centers (a) façade (b) perspective view of the street is $\mathrm{D}+1 \mathrm{~m}$, with insolation $2086,6 \mathrm{Wh} / \mathrm{m}^{2}$ (Figure 2). It can be noticed that by using algorithm, favourable distribution of trees on footway, decreased the façade insolation by $2 \%$.

In Figure 3, the relationship between the distance between trees' centers on footway and the level of insolation on the façade is presented. It can be noticed that for maximal trees' distances, $\mathrm{D}+5$, the level of insolation is the highest. Due to this, it can be concluded that such distribution of trees often used in urban planning would not provide the maximal overshadowing on the façade in case of the street similar to the one presented.

In the same example the surface of footway is also included in solar simulations. The footway is placed in front of the façade with maximal distance between the trees, D+5m, with insolation level of 2329,2 Wh/ $\mathrm{m}^{2}$ (Figure 4). With the algorithm application, the most favourable distribution is detected, the one with trees' distances $\mathrm{D}+0.8 \mathrm{~m}<$, with insolation level of 2181,9 Wh/m $/ \mathrm{m}^{2}$ (Figure 5). The amount of insolation is decreased 147,2 Wh/m, i.e. the improvement of overshadowing is by $6,32 \%$.

Compared with other trees' distances, it can be noticed that the highest level of solar insolation is with the maximum trees distances, D+5 (Figure 6).

a)
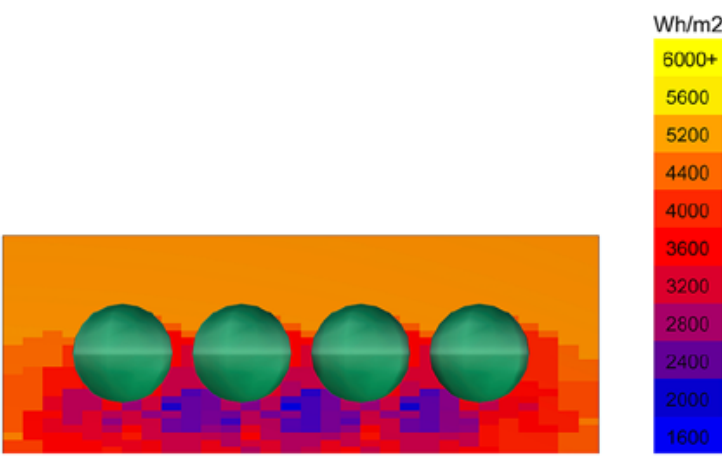

b)

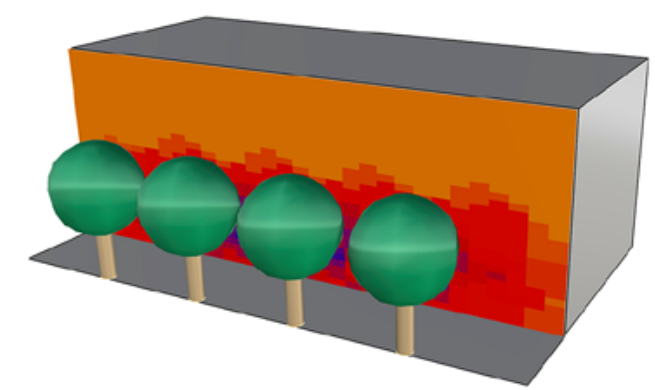

Figure 2. Insolation of the façade with distance between trees centers $D+1 m$ (a) façade (b) perspective view of the street 


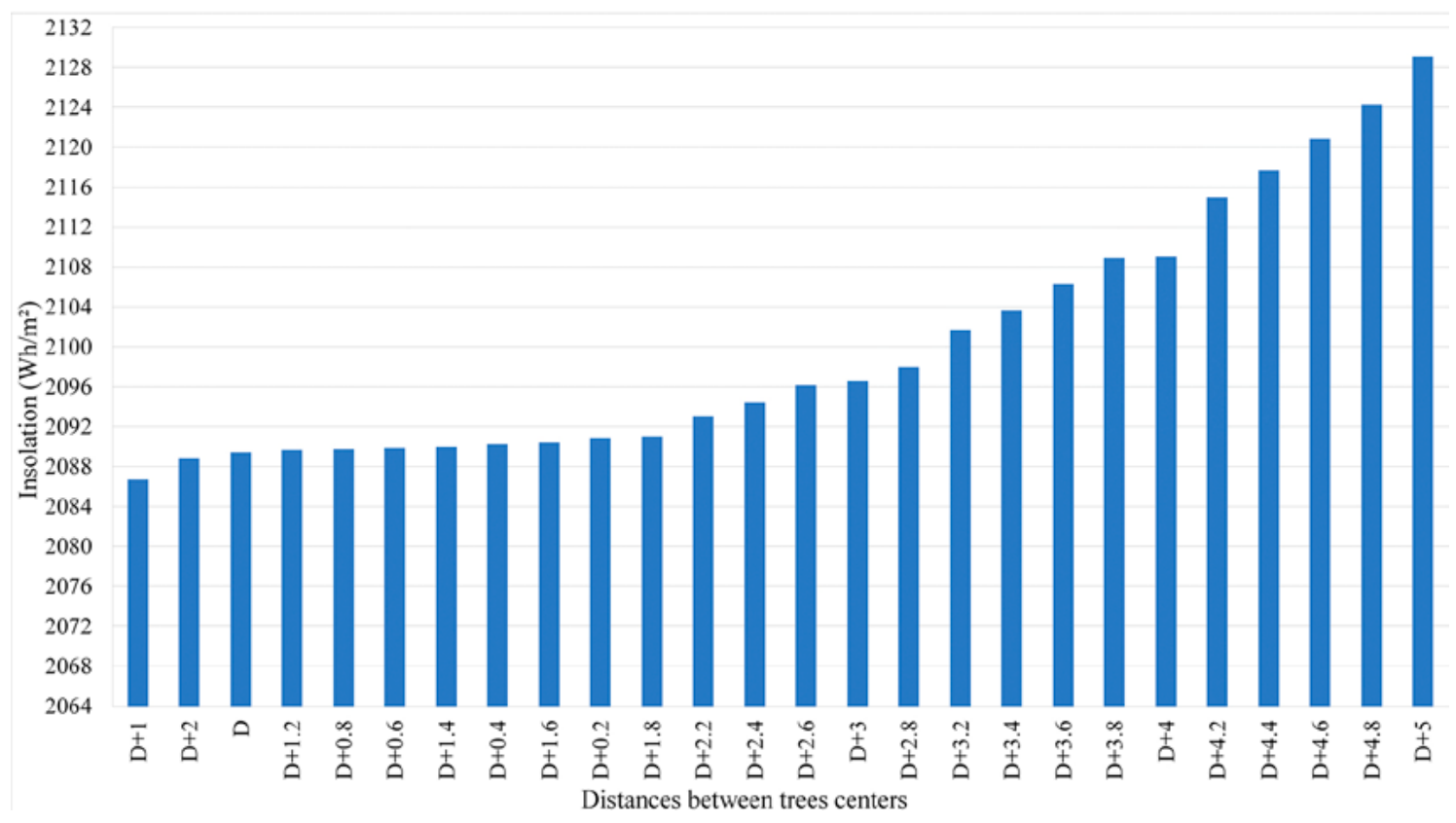

Figure 3. Level of insolation of the façade for different distances between trees centers

a)

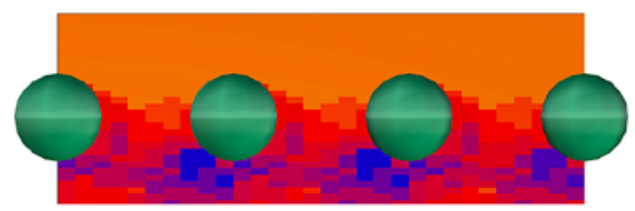

b)

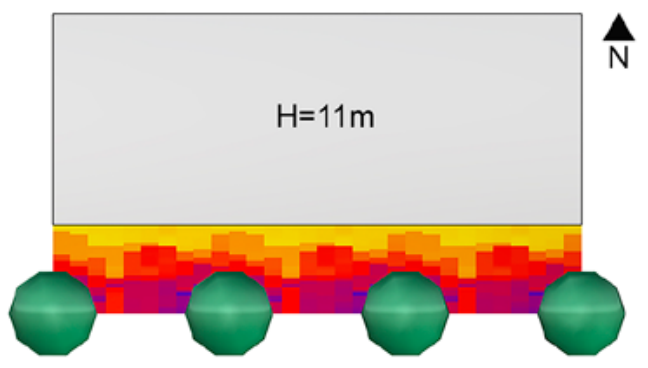

c)

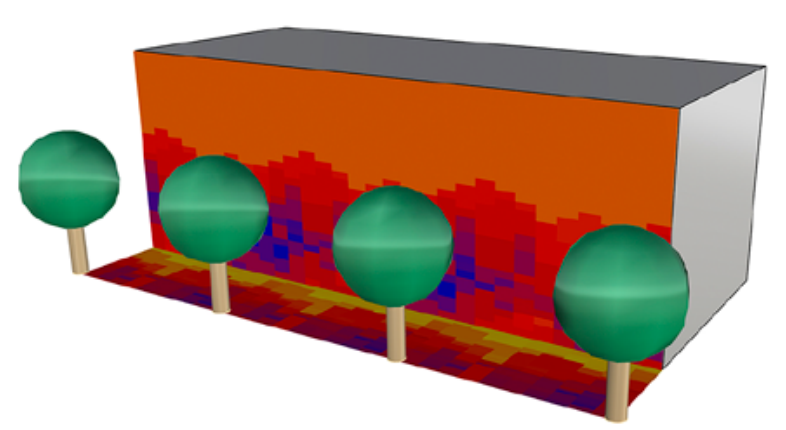

Figure 4. Insolation of the façade and footway with maximal distance between trees centers (a) façade (b) footway and $(c)$ perspective view of the street

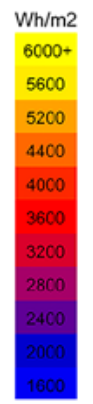

Wh/m2 $6000+$ 5600

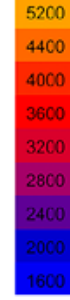

4400

4000

3200

1660

) a)

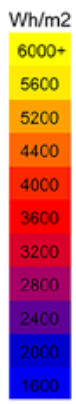

b)

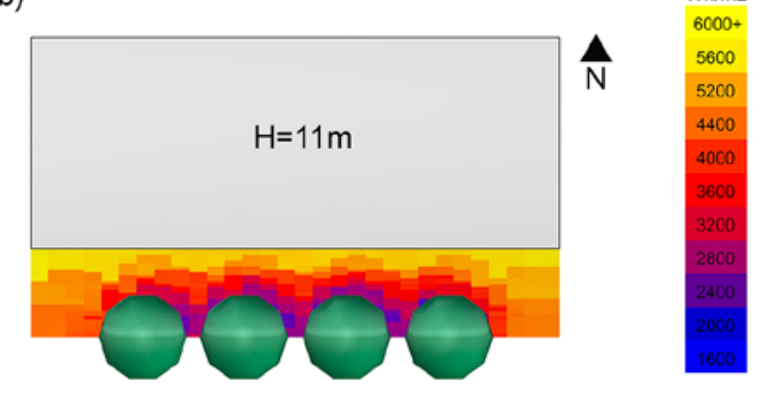

c)

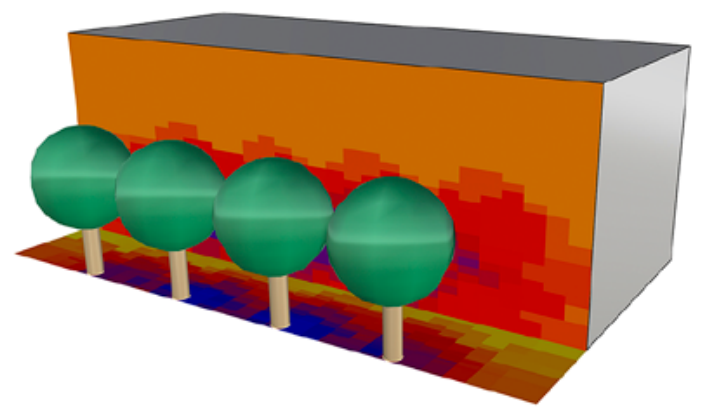

Figure 5. Insolation of the façade and footway with distance between trees centers $D+0.8$ (a) façade (b) footway and (c) perspective view of the street 


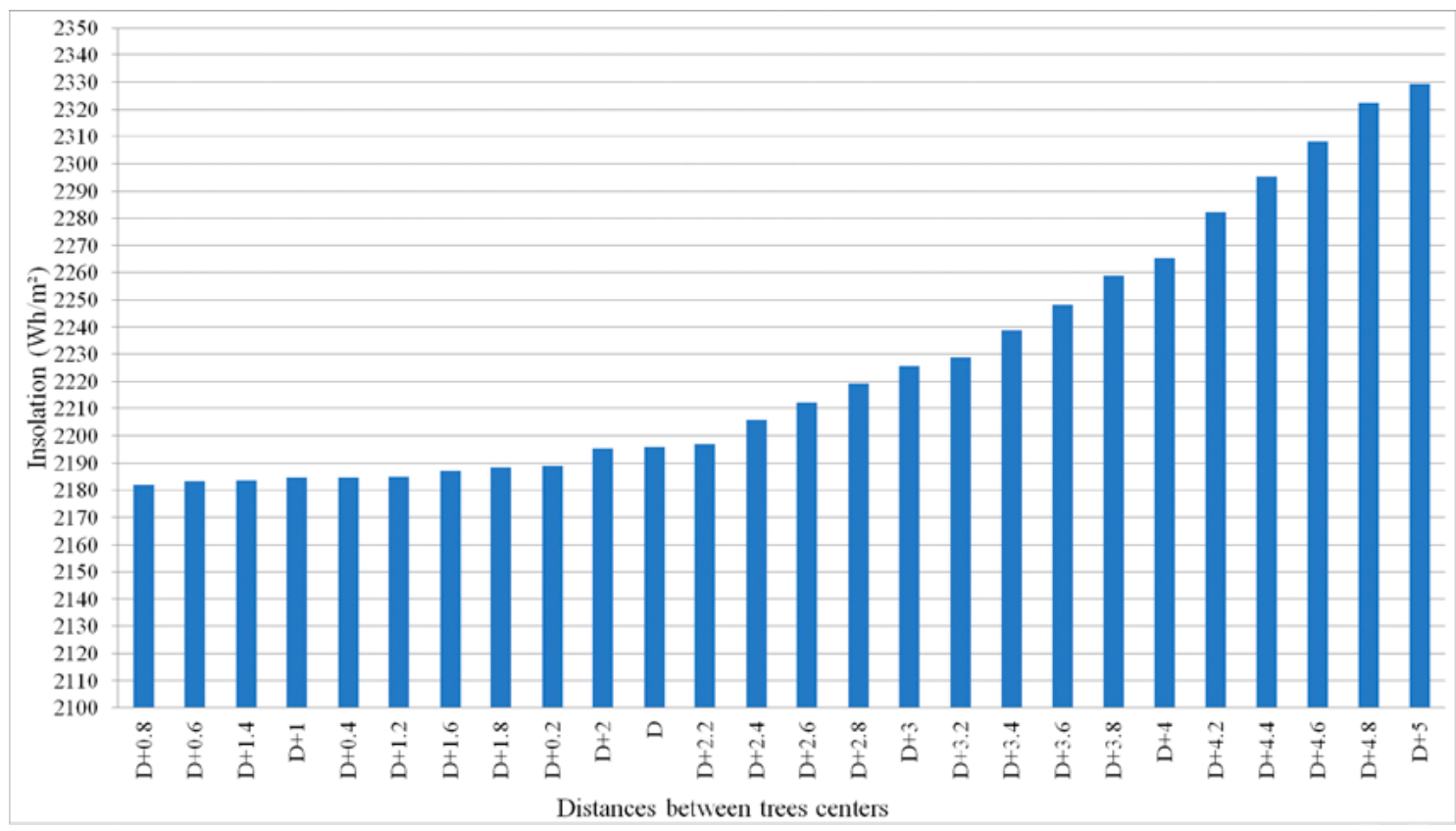

Figure 6. Level of insolation of the façade and footway for different distances between trees centers

In the next street example, the footway is located $12 \mathrm{~m}$ meters away from the building to notice results when the footway is not next to the building, with maximum distances between trees, $\mathrm{D}+5 \mathrm{~m}$, with insolaton level of $1945,8 \mathrm{Wh} / \mathrm{m}^{2}$ (Figure 7). When the simulations of insolation are performed, favourable trees' locations were moved to the right side, and the distances between trees are $\mathrm{D}+1 \mathrm{~m}$, with insolation level of 1830,1 Wh/m² (Figure 8). The software for solar simulations takes into account that the left part of the

a)

$\hat{N}$

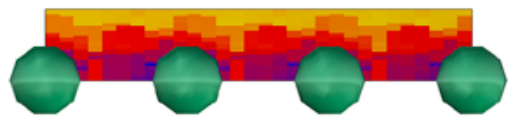

$H=11 \mathrm{~m}$

b)

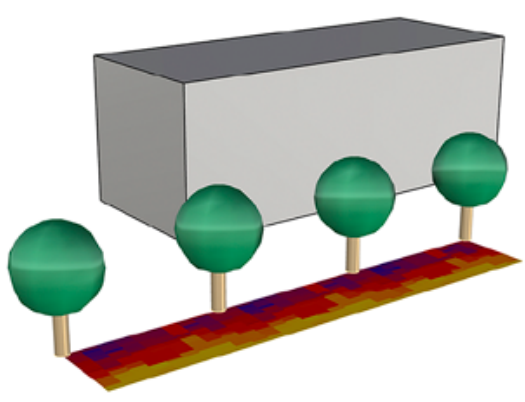

Figure 7. Insolation of the footway with maximal distance between trees centers (a) footway and (b) perspective view of the street footway is overshadowed by the building, and due to this the trees are placed on the right side. The improvement in solar insolation mitigation is $6 \%$.

Important factor for overall insolation influence is street orientation. The analysis of the same street, same geometry, same footway, same number of trees, same distances between trees, but different orientation (Figure 9) is performed to highlight the importance of orientation. The current insolation level with maximal distances between trees is $1368,8 \mathrm{Wh} / \mathrm{m}^{2}$. By

a)

$\hat{N}$
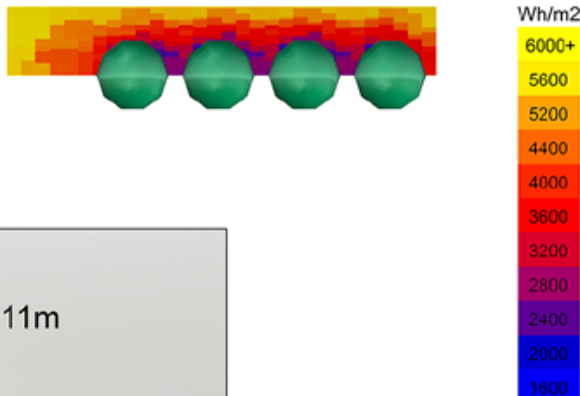

b)

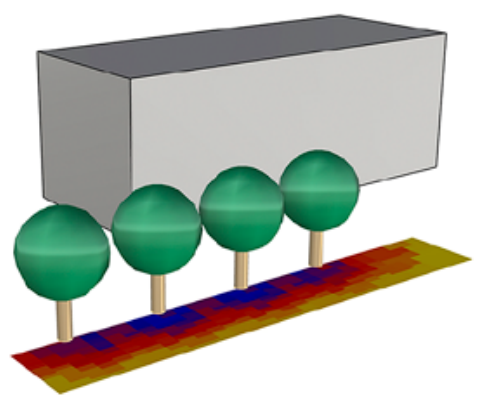

Figure 8. Insolation of the footway with distance between trees centers $D+1 \mathrm{~m}$ (a) footway and (b) perspective view of the street 
a)

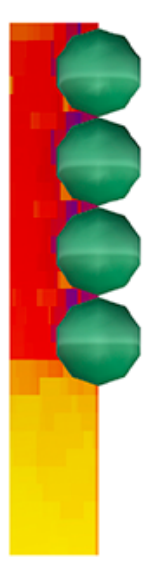

b)

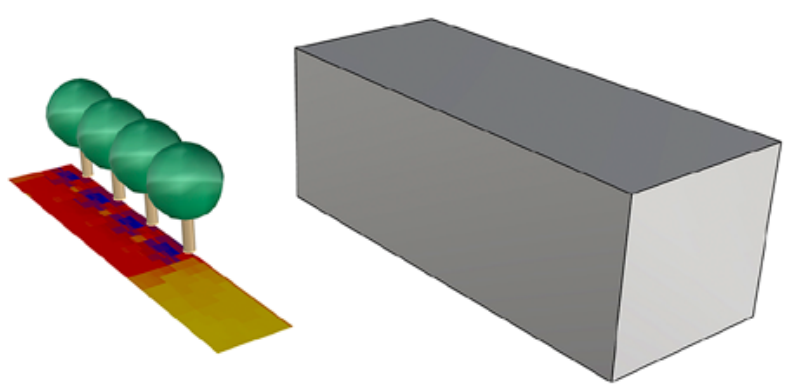

Figure 9. Insolation of the footway with maximal distance between trees centers (a) footway and (b) perspective view of the street

using algorithm in N-S orientation it can be noticed that the insolation level of the footway decreased up to $6,35 \%$. The most favourable distance obtained by algorithm is D, with insolation level of $1281,8 \mathrm{Wh} / \mathrm{m}^{2}$ (Figure 10). Also, position of trees is different depending of the orientation. a)

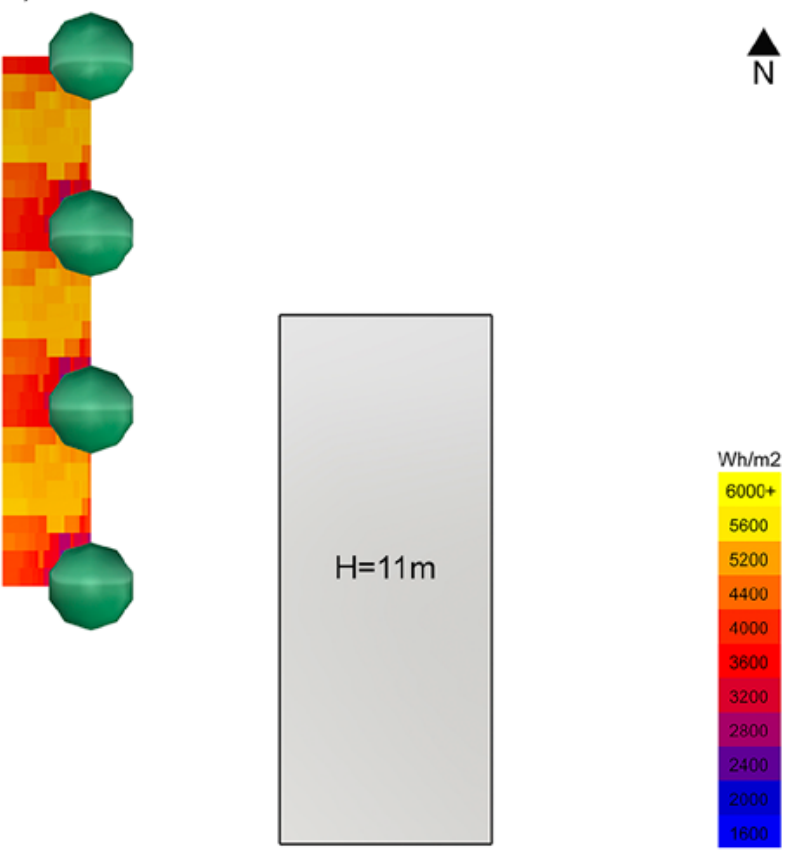

b)

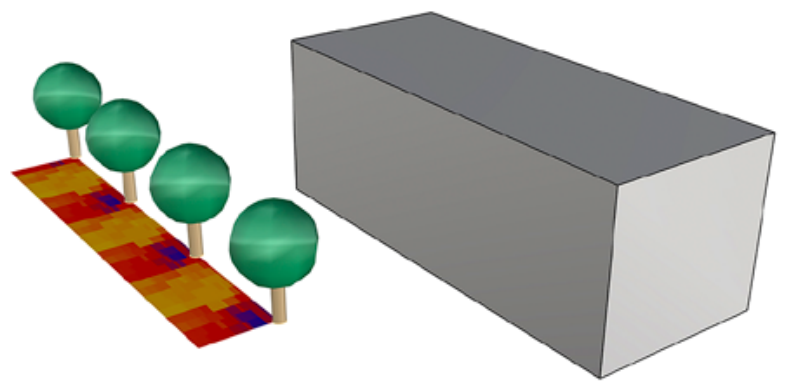

Figure 10. Insolation of the footway with distance between trees centers $D(a)$ footway and (b) perspective view of the street

If the orientation of the street $\left(45^{\circ}\right)$ as shown on figure 11, the location of the trees and favourable trees' distance will be different. Insolation level in this case is $2891,7 \mathrm{Wh} / \mathrm{m}^{2}$. In figure 12 it can be seen that the favourable distances between trees changed to $\mathrm{D}+2 \mathrm{~m}$ and the insolation level is $2734,3 \mathrm{Wh} / \mathrm{m}^{2}$ and insolation decreased by $5,45 \%$. 
a)

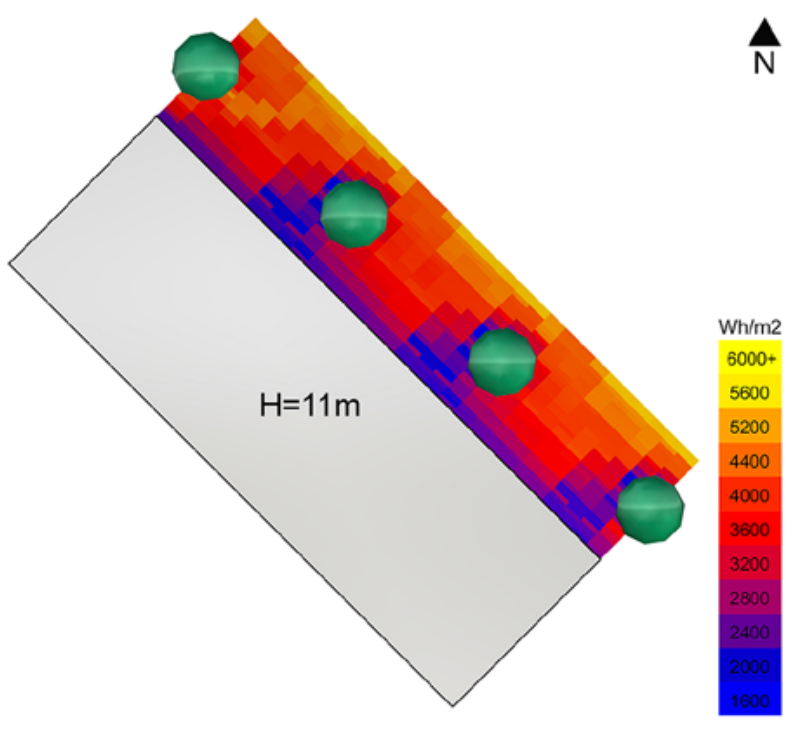

b)

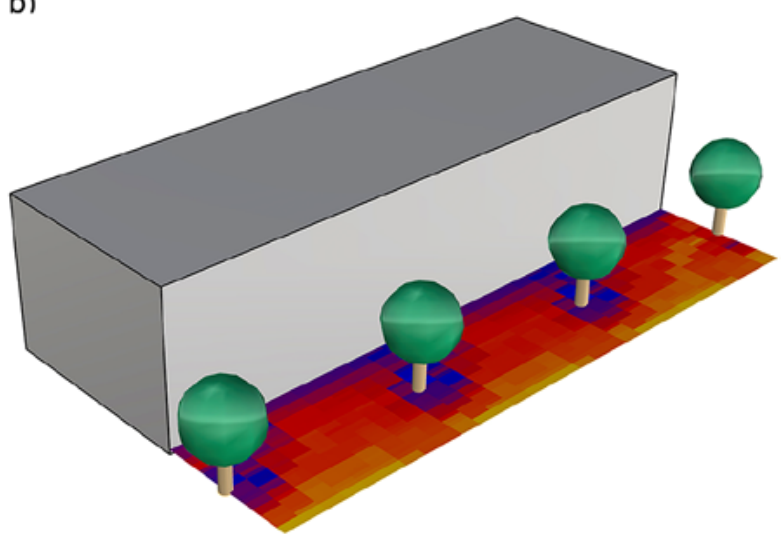

Figure 11. Insolation of the footway with maximal distance between trees centers (a) footway and (b) perspective view of the street a)

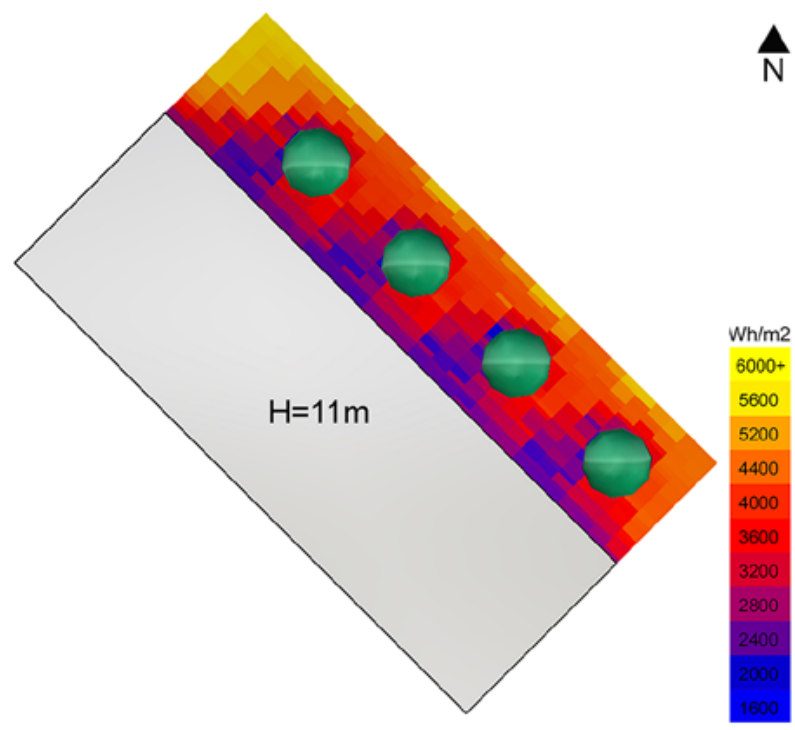

b)

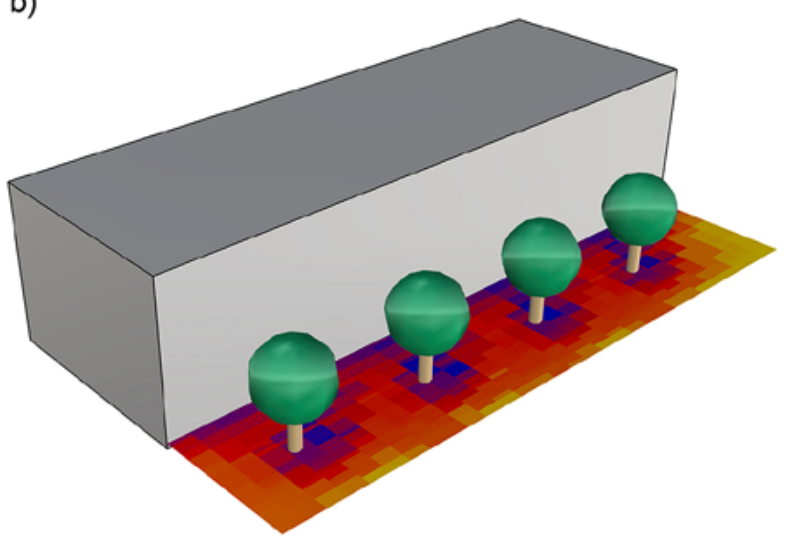

Figure 12. Insolation of the footway with distance between trees centers D+2m (a) footway and (b) perspective view of the street

\section{Conclusions}

In this paper various software applications are combined to enable processing of the data and automated changing of the geometry. By using this approach, the level of insolation at footways and façades can be reduced up to $7 \%$. Accordingly, the urban microclimate can be improved and be more comfortable during summer.

This algorithm can be used for any world location, by using appropriate climate data. Also, any geometry of the building, with any orientation, can be created and parameterized and used in the algorithm. Except spherical, other geometries of the trees can be used, such as ellipsoid, cylindrical or conical depending of the shape of the urban greenery which should be planted in particular environment. Ability to change these geometrical parameters contributes to wide us- ability of algorithms such as the one presented in this paper for adequate trees planting in any street.

Approach in this paper allows better cooperation among architects and urban planners as well as landscape designers in the beginning of urban planning process, in order to create an environmentally conscious urban design that minimize the level of insolation of building façades and footways in streets.

The limitation of this approach is simplification of the geometry and the complexity of the street environment in order to perform large amount of simulations in short time period. The façades are represented as flat planes and the insolation is measured only in street façade while the side ones are ignored. The real trees' parameters, such as leaf density, transparency and transpiration are not taken into consideration. 
The future research refers to investigate similar problems in urban environment for various types of urban surfaces. Similar algorithms can be applied in different city locations (e.g. parks, courtyards, squares) in order to decrease insolation level and improve well-being benefits in these open spaces.

\section{References}

Ali-Toudert F, \& Bensalem R. (2001). A methodology for a climatic urban design. Proceedings of the 18th conference on PLEA, Florianopolis, Brasil, 7-9 November 2001. p. 469-73.

Ali-Toudert, F., \& Mayer, H. (2006). Numerical study on the effects of aspect ratio and orientation of an urban street canyon on outdoor thermal comfort in hot and dry climate. Building and Environment, 41(2), 94-108.

Amado, M., \& Poggi, F. (2014). Solar urban planning: A parametric approach. Energy Procedia, 48, 15391548.

Andreou, E. (2014). The effect of urban layout, street geometry and orientation on shading conditions in urban canyons in the Mediterranean. Renewable Energy, 63, 587-596.

Andreou, E., \& Axarli, K. (2012). Investigation of urban canyon microclimate in traditional and contemporary environment. Experimental investigation and parametric analysis. Renewable Energy, 43, 354-363.

Bajšanski, I. V., Milošević, D. D., \& Savić, S. M. (2015). Evaluation and improvement of outdoor thermal comfort in urban areas on extreme temperature days: Applications of automatic algorithms. Building and Environment, 94, 632-643.

Bajsanski, I., Stojakovic, V., \& Jovanovic, M. (2016). Effect of tree location on mitigating parking lot insolation. Computers, Environment and Urban Systems, 56, 59-67.

Baker, L. A., Brazel, A. J., Selover, N., Martin, C., McIntyre, N., Steiner, F. R., Nelson, A \& Musacchio, L. (2002). Urbanization and warming of Phoenix (Arizona, USA): Impacts, feedbacks and mitigation. Urban ecosystems, 6(3), 183-203.

Chan, A. T., So, E. S. P., \& Samad, S. C. (2001). Strategic guidelines for street canyon geometry to achieve sustainable street air quality. Atmospheric Environment, 35(24), 4089-4098.

Chatzidimitriou A., \& Yannas, S. (2017). Street canyon design and improvement potential for urban open spaces; the influence of canyon aspect ratio and orientation on microclimate and outdoor comfort. Sustainable Cities and Society, 33, 85-101.

De Abreu-Harbich, L. V., Labaki, L. C., \& Matzarakis, A. (2015). Effect of tree planting design and tree species on human thermal comfort in the tropics. Landscape and Urban Planning, 138, 99-109.

Grasshopper, https://www.rhinozd.com/6/new/grasshopper, accessed 2019-11-25

Horvat, M., \& Dubois, M. C. (2012). Tools and methods for solar design-an overview of IEA SHC Task 41, Subtask B. Energy Procedia, 30, 1120-1130.

Milošević, D. D., Bajšanski, I. V., \& Savić, S. M. (2017). Influence of changing trees locations on thermal comfort on street parking lot and footways. Urban forestry \& urban greening, 23, 113-124.

Milošević, D. D., Savić, S. M., \& Bajšanski, I. V. (2017). Applications of automatic algorithms for improvement of outdoor thermal comfort in cities. Procedia engineering, 198, 187-192.

Oke, T. R. (1988). Street design and urban canopy layer climate. Energy and buildings, 11(1-3), 103-113.

Picot, X. (2004). Thermal comfort in urban spaces: impact of vegetation growth: Case study: Piazza della Scienza, Milan, Italy. Energy and buildings, 36(4), 329-334.

Simpson, J. R. (2002). Improved estimates of treeshade effects on residential energy use. Energy and Buildings, 34(10), 1067-1076.

Taleghani, M., Sailor, D., \& Ban-Weiss, G. A. (2016). Micrometeorological simulations to predict the impacts of heat mitigation strategies on pedestrian thermal comfort in a Los Angeles neighborhood. Environmental Research Letters, 11(2), 024003. 